\title{
The Learning on CRM in ERP- with Special References to Selected Engineering Companies in Gujarat
}

\author{
Mehul Patel, Manisha Ben Jaiswal
}

\begin{abstract}
ERP is enterprise administration software-typically a suite of built-in applications-that a agency can use to collect, store, manipulate and interpret facts from many enterprise activities, including: product planning, cost, manufacturing or carrier delivery, advertising and sales. Most of the agencies both MSMEs and massive scale groups have integration interfaces between ERP and CRM structures for the change of patron and income data. In latest years there has been a blurring of the distinctions between ERP and CRM systems. Most ERP structures have elevated to fundamental performance for CRM and Management Information Systems (MIS). Similarly, CRM structures now consist of a great deal commonplace ERP functionality. The whole CRM-ERP integration oriented engineering groups are 143 in Gujarat. The decision of 15 agencies is made feasible on the groundwork of 5 zones of Gujarat State. The supply of information is principal and secondary. The foremost statistics are amassed thru structured questionnaire administered to the respondents in individual and thru email. The legitimate pattern dimension for this find out about is decided on the foundation of the aforesaid formulation for the pattern size. The populace for deterring is in variant mode 3803 by means of getting records via net hyperlinks and private assembly with organization authorities. The pattern measurement may additionally be decided as 372. IBMSPSS.22 is employed as a statistical device for the reason of information analysis. Demographic frequency of respondents, scale reliability test, correlations, component evaluation and regression evaluation are performed as statistical checks for attaining the objectives.

Keywords: CRM the commercial enterprise focus, appropriateness, Information Quality, System Quality, System Use
\end{abstract}

\section{INTRODUCTION}

The evolution of ERP has regularly been used in the educational literature to describe the thought of corporation structures (ES) (Mc Gaughey\&Gunasekaran, 2007)1. Enterprise systems, additionally many times referred to as ERP structures (Davenport, 1998)2, have their starting place in the early 50's. It used to be with the introduction of computer systems into the enterprise that the first functions started to emerge. At first these functions have been used for automating guide methods like bookkeeping and stock management.

Revised Manuscript Received on April 15, 2020.

* Correspondence Author

Dr. Mehul Patel*, Assistant Professor, C P PATEL \& F H SHAH Commerce College, Anand Email:- mehul29978@gmail.com

Manisha Ben Jaiswal, Researcher and IT Consultant, MD, USA, Pursuing Ph.D. University of Cumberland, KY, USA, IT Consultant, MD, USA

(C) The Authors. Published by Blue Eyes Intelligence Engineering and Sciences Publication (BEIESP). This is an open access article under the CC BY-NC-ND license (http://creativecommons.org/licenses/by-nc-nd/4.0/)
The use was once increased in the course of the 60's to Inventory Control Systems (ICS) and Bill-of-Material (BOM) planning which in flip progressively grew to become standardized into Material. Requirements Planning (MRP). During the 70's new software program structures had been brought with the emphasis on the optimization of the manufacturing processes. These structures synchronized the fabric necessities with the manufacturing necessities and grew to become recognized as Manufacturing Resource Planning (MRP II)systems. The manufacturing procedure optimization used to be developed in the structure of the Computer-Integrated Manufacturing (CIM) thinking in the 80's. Even although the CIM thoughts failed in many aspects, the research, e.g. on data structures improvement (ISD) and agency models, supplied the history for regularly integrating extra areas into the scope of the

records structures (Møller, 2005)3. The elevated scope of records structures paved the way for ERP systems, which furnish a software program package deal designed to combine the inside value-chain of an enterprise, masking enterprise procedures from manufacturing to transportation as nicely as secondary procedures like accounting and finance. In the late 90's suppliers started to add extra modules and performance to the core modules of the ERP systems.

These extensions to the ERP machine encompass Advanced Planning and Scheduling (APS), Customer Relationship Management (CRM) and Supply Chain Management (SCM). The core ERP modules mixed with the aforementioned extensions grew to become recognized as Extended Enterprise Resource Management (X-ERP) (Rashid et al., 2002). Currently we are seeing that ERP II is nonetheless evolving. Bond (2000) describes the cause for this evolution as: "Enterprises are starting to transforms themselves from vertically built-in agencies centered on optimizing interior company features to more-agile, corecompetence-based entities that try to function the corporation optimally in the provide chain and the cost network." The positioning of the employer ought to be regarded in a broader context then simply dyadic family members in the structure of $\mathrm{B} 2 \mathrm{C}$ or $\mathrm{B} 2 \mathrm{~B}$. Instead, the collaborative commerce definition as given with the aid of Gartner lookup team (Bond et al., 2000) has to be taken into account. It states that "E-commerce includes the collaborative, electronically enabled enterprise interactions amongst an enterprise's interior personnel, commercial enterprise companions and clients in the course of a commercial enterprise or trading". In essence, this ability firms role themselves. Optimally in the provide chain and the cost community via capability of digital auctions and different one-to-many or many-to-many relations. (Markus et al., 2000). 
An ERP (Enterprise Resource Planning) machine is series of offerings and automation to automate, display and music the sources of an organization. Contrary to the feature of a CRM system, an ERP machine is shut to the enterprise and listing all the offerings and merchandise to promote as nicely as continues tune of inside belongings of the organization. We can say that ERP is backend of CRM system, the place CRM device and its features are greater seen to outer world than an ERP however all the processing ofsales transitions initiated through a CRM is no longer feasible to execute barring an environment friendly ERP machine at the backend. The organizations chosen for this learn about are the usage of ERP for monetary and product growth.

Marketing: The advertising branch is accountable for bringing in the clients for business. There are normally two strategies observed in the business enterprise beneath Learning.

1) Direct advertising and 2) Alliance marketing.

Direct advertising is a principal advertising approach used via companies of all sizes, the place a goal target market is chosen and thru an geared up advertising technique organization message is delivered to this audience. The CRM device helps us to attain goal target market by means of Email advertising and marketing campaigns, Social media advertising campaigns and direct cellphone marketing. All these advertising transactions are recorded in a centralized CRM device so human beings working in exclusive groups and places have get admission to up-to date advertising and marketing popularity of any customer.

Alliance advertising is an imply the place different companies pool collectively their customer assets and shares the attainable purchaser information. Alliance entrepreneurs have a restrained get admission to our CRM and ERP machine the place they can register this information. If a client is added via an alliance accomplice and that purchaser clearly buys the product then alliance companion is given a predetermined share of the revenue. This income distribution is tracked the use of ERP system.For each Alliance and Direct advertising and marketing CRM machine will host advertising and marketing statistics beginning as "Marketing lead". Marketing lead is the preliminary entry factor of a doable consumer in the system. Once a advertising and marketing lead is realized to have the attainable of an proper sale then it is transformed to a "Sales opportunity", at this factor advertising and marketing branch palms over the transaction to Sales department.

Sales: Sales branch is accountable for promoting the product and bringing in the revenue. Once a "Sales opportunity" is created in CRM gadget then income branch takes over the procedure and starts offevolved a one to one coordination with the customer. An income chance goes thru distinct phases of sales.

After income help and forecasting: After income aid segment starts offevolved as soon as a income deal is thru and client has bought the product. Using the identical CRM gadget clients can register their guide requests and income branch can delegate those requests to associated departments. One extra essential income step known as product forecasting is performed at this stage and all the income statistics and purchaser records is used to analyze and predict the future income and income achievable with an existingcustomer. Forecasting module is phase of CRM gadget and helps Sales and advertising and marketing branch to streamline the future strategy.
ERP Process: ERP is managed and operated via Accounts, Revenue and Finance departments, so all ERP methods observe the operation of these departments. In the following paragraphs we will damage down the performance of ERP by using special departments of a company the use of this system. First we will supply the reasoning of use then we will short that how an ERP is used in sure department.

Accounts: The bills branch manages and video display units all head of money owed in the organization. Accounts branch data accounts-payable and receivable, payroll, constant assets, stock and all different economic elements. An ERP device is the important machine of use in bills department. ERP will preserve all the money owed facts for inner belongings and liabilities. To facilitate the debts branch and to limit the component of human error in economic figures, ERP has computerized some tedious accounting tasking for instance automated income focus entries and belongings depreciation entries.

Revenue: Revenue branch is the bridge between CRM and ERP systems. Once a income chance is negotiated in CRM and it concludes on a viable sale then a Quote is created in ERP system. A quote small print extra particular and exact data about the sale. All that exact and granular facts is solely handy in ERP system. This factor requires many validations and synchronization of facts between two systems. Creating a quote would possibly set off some approval methods inside the organization. These approvals are some other way of making sure the facts validity andconsistency between each CRM and ERP structures as nicely as income adherence to organizational insurance policies and worldwide laws. Once a quote is subsequently agreed upon and signed by means of the client that outcome in profitable income transaction. This transaction will additionally set the chance repute to "Closed won" in CRM system. In case the transaction does now not give up in a profitable sale then possibility is set to "Closed lost" status.

Finance: Finance branch is accountable to guarantee an easy income float in the organization. To accomplish the clean income drift Finance has to screen and audit all the income transactions going on in the organization. Finance branch makes positive that all the economic figures in the ERP gadget are correct, in this way they assist and complement money owed branch to make a steady and auditable ERP system.

The feature of Finance branch begins from the consciousness of a patron in CRM the place patron background, savings records and different economic constraints are checked. If a Quote is created in the ERP device with unique and out of the norm monetary phrases that requires approval from finance earlier than intending to the income agreement. After the sale transaction finance will bill the client and make positive that for a software program product a legitimate license is delivered to the consumer and client ispaying as per the agreement.

CRM and ERP gadget integration is really useful to any organization. It drives to increased productiveness by using producing duplication of statistics entry duties empowering worker with the proper records at proper time, move alizing commercial enterprise tactics via atomized workflow and enhancing organizational venture management. Many smallto-midsized companies use

Published By:

Retrieval Number: H0798044820 /2020@BEIESP

DOI: 10.35940/ijmh.H0798.044820

Journal Website: www.ijmh.org
Blue Eyes Intelligence Engineering \& Sciences Publication (C) Copyright: All rights reserved. 
CRM and ERP options to automate and enhance the administration of their operations. CRM is a front-office gadget that centralizes all data about exterior marketing, manages the income pipeline, automates patron service, tracks data about customers, as nicely as creates dashboards and reviews on this data. ERP structures automate and manipulate back-office enterprise activities, such as accounting, purchasing, collections, human resources, payroll, manufacturing, distribution, and more. Older, pointto-point integration strategies can be costly, complex, and risky. Even when a organization does combine these systems, future CRM or ERP enhancements can without difficulty render the integration inoperable. As a result, many groups functions CRM and ERP as standalone systems. Solutions are now reachable that combine CRM and ERP structures out of the box. These built-in options get rid of the want to operate complex, time-consuming and expensive point-to-point integrations - and the challenges of upgrading structures built-in in this manner.
Using built-in CRM-ERP solutions, groups attain get entry to complete and regular records about clients from for the duration of the corporation the use of their accustomed application. This built-in data permits customer to view mixed economic and nonfinancial statistics about clients from inside the CRM application, regardless of the place the records is generated or stored. These blended options additionally carry collectively formerly disconnected enterprise approaches by means of automating complex, multistage procedures in an end-to-end manner. In different words, these built-in structures furnish "straight through" processing. They appoint workflow administration and can mechanically set off the gorgeous downstream commercial enterprise process, passing information seamlessly from one utility to the subsequent besides guide intervention. For example, built-in options can tie collectively the quote-toorder and order-to-cash procedures into a complete quote-tocash technique that eliminates the want to rekey information

\section{CRM: The Business Focus}

\section{Supports an Integrated and Collaborative Relationship Between a Business and it's Customers}
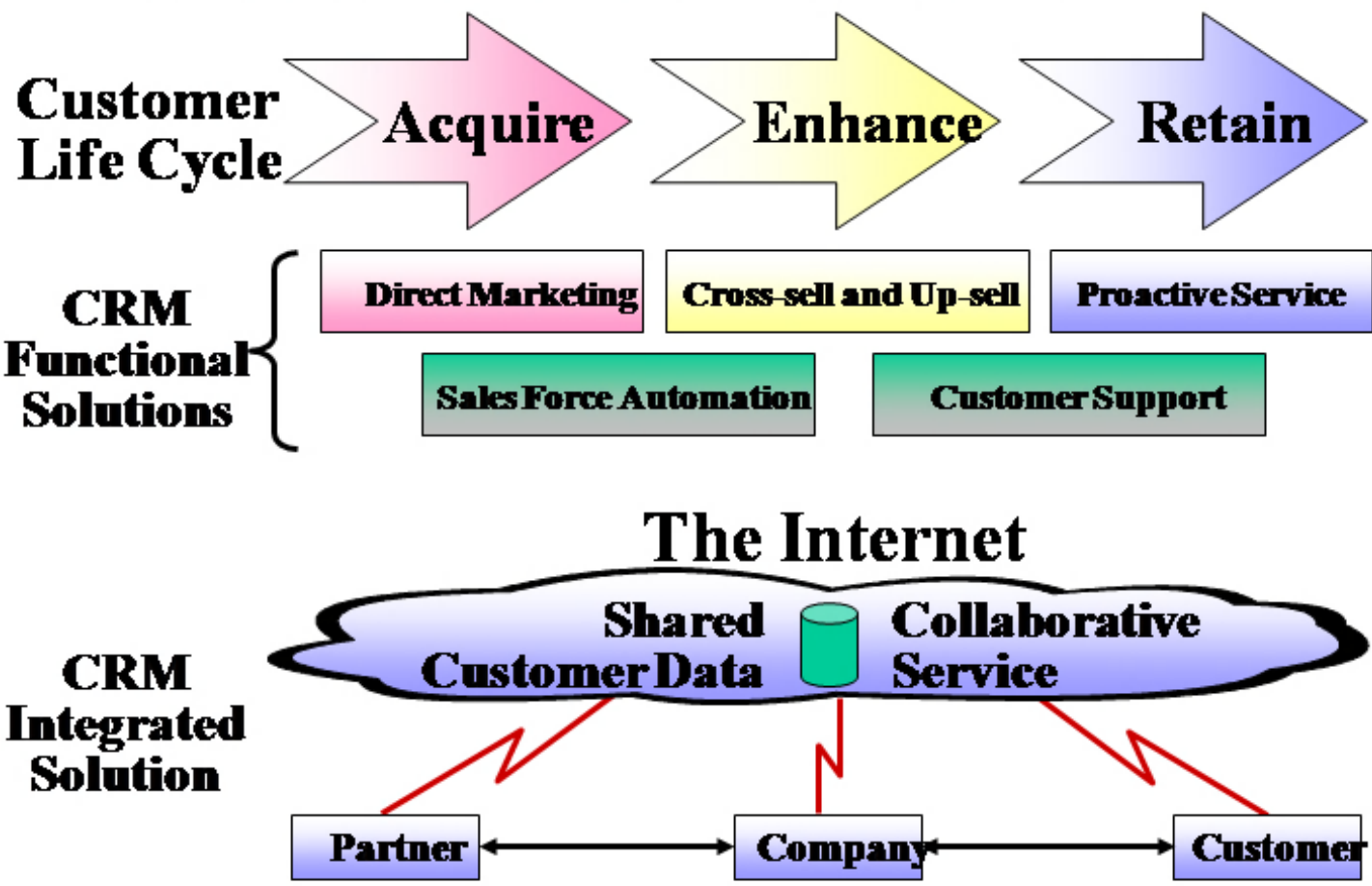

Apart from the theoretical background of ERP and CRM system, this Learning examinesthe relations between elements of CRM: The Business Focus factor and other factorslike; information quality, system quality, system use and appropriateness of systemsused by various selected engineering companies of Gujarat State. This can be shownin a diagram form for better understanding 


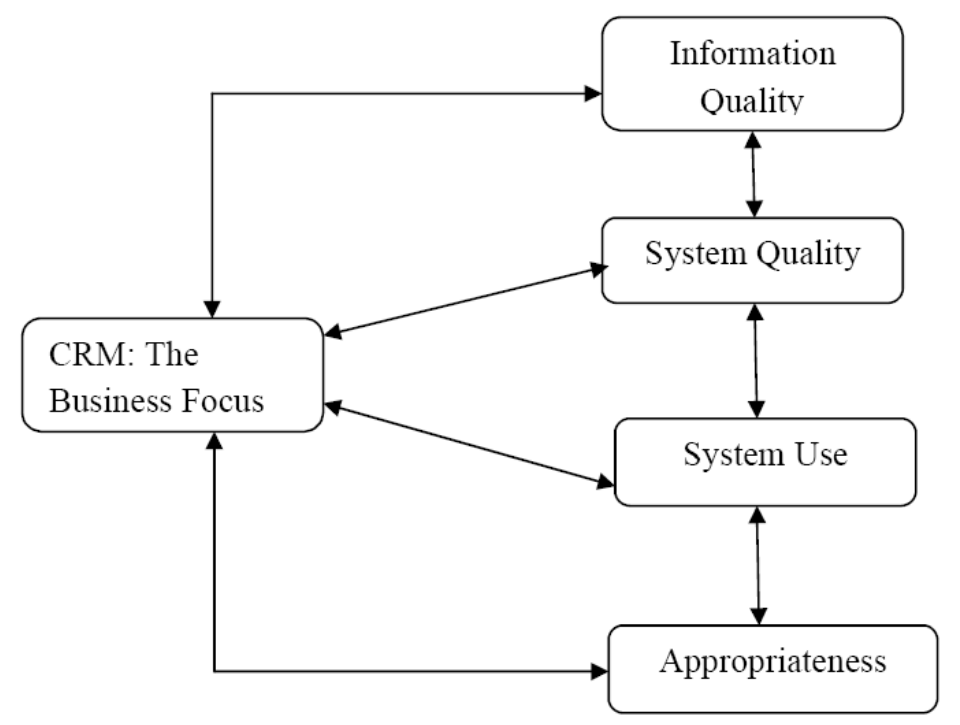

Profile of Selected Engineering Companies

The engineering companies for this investigation are selected from the differentdistricts of Gujarat State. The list of 15 selected engineering companies are as follows.

\begin{tabular}{|lll|}
\hline No & Company Name & Destination \\
\hline 1 & Power Build Ltd. ELECON & Anand \\
\hline 2 & Rotomag Motors \& Controls Pvt Ltd & Anand \\
\hline 3 & Ferro-tic Dyes and Moulds & Vadodara \\
\hline 4 & FAG Bearings India Ltd. & Vadodara \\
\hline 5 & Pyron Engineers Pvt Ltd. & Ahmadabad \\
\hline 6 & Ambica Engineering Company & Ahmadabad \\
\hline 7 & Neptune Engineering Company & Mehsana \\
\hline 8 & Regal Engineering Company & Rajkot \\
\hline 9 & White wagon Pvt Ltd & Rajkot \\
\hline 10 & Alang Auto \& Gen. Engineering Company & Bhavnagar \\
\hline 11 & Deep Jyoti Hydraulic Engineering Company & Ankleshwar \\
\hline 12 & ExzaktaMechanica Ltd. & Ankleshwar \\
\hline 13 & Analpa Industries. & Ankleshwar \\
\hline 14 & Zuberi Engineering Company & Kutchh \\
\hline 15 & Heavy Engineering Kalthia Group & Kutchh \\
\hline
\end{tabular}

\section{LITERATURE REVIEW}

Enterprise Resource Planning (ERP) structures have emerged as the centre of profitable statistics administration machine and are viewed as the spine of organizations. In this world enterprise scenario, businesses of any magnitude have both carried out or are in the system of enforcing ERP structures in order to continue to be competitive. ERP can be viewed as distinctly built-in administration facts gadget having the functionality to control all factors of commercial enterprise operationsof organizations, which encompass production, manufacturing, sales, accounting, purchaser service, etc. According to Gable \&amp; Stewart, (1999): ERP is more and more turning into common platform for the small and medium scale industrial sectors and is seen as one of the approaches to obtain aggressive benefit and to reengineer commercial enterprise process. Wang et al., (2010): to attain synergy throughout product lines, these groups have to put into effect a set of widespread commercial enterprise functions and constant facts definitions throughout all enterprise units. ERP applications are extremely beneficial for integrating a corporation at the international stage and for imparting a "common language" during the organization). Indian small and medium enterprise is additionally affected with such scenario. However, the giant enterprises have tried to handle in their personal way and it is the small and the medium scale corporations (SME) that are displaying their large plausible increase the use of ERP. Indian SMEs make contributions nicely above $60 \%$ of country's gross home product (GDP) and, due to the fact of its possible boom ERP providers are shifting their interest toward small and medium commercial enterprise (SMB) through supplying custom-made and less expensive options from each the organizational and technological factor of view Chen, (2001).According to (Mabert et al, 2001); Koh \&amp; Simpson, (2007): SME creates the greatest employment possibilities for the Indian population.

Published By:

Blue Eyes Intelligence Engineering \& Sciences Publication 
India's SME region is a vibrant, dynamic, bendy and productive entity, containing as many as 12 million devices and using round 30 million people. At the time of elimination of quantitative restrictions beneath WTO in 2001, it was once broadly feared that this zone would give way underneath the onslaught of world products. On the contrary, the region rapidly tailored and restructured itself to face the opposition head-on.

It embraced excessive technology, popular norms of exceptional and competitiveness and persisted to extend quicker than the relaxation of the industrial economy. A tremendous majority of small and medium scale groups have some huge constraints in their resources. While Indian SMEs neglect the advantages of integrating ERP structures declaring that such ERP software program are past their budgets as the reason, however there is no doubt that theimplementation of ERP software program can enhance the company's overall performance as well. The cognizance of enforcing corporation commercial enterprise utility (i.e. ERP) amongst SMEs is much less than $35 \%$, as in contrast to over $80 \%$ for giant businesses as per survey performed with the aid of International Data Corporation (IDC). The vital influencing commercial enterprise drivers for SME section expand the standard commercial enterprise efficiency, expand the capital and labor productiveness and to limit the constant and variable cost. Research and survey via main IT companies simply factors out that the want for technological know-how options is no longer solely constrained to metro cities in India however additionally commercial enterprise businesses running from city and Sub city vicinity additionally want ERP options as well. As all ERP companies are focusing on this market, the Indian SME section will have many choices to select any one out of these having one of a kind aggressive price. It has been observed from the result of numerous researches that the implementation of ERP structures is extra complicated and pricey assignment for small organizations.

According to Leonard Simon (1997), the ERP paradigm shift is a end result of demand from industries for bendy and built-in statistics structures and exploitation of data technological know-how developments such as Relational Data Bases, Client $\backslash$ Server computing, Object Oriented Network and Graphical User Interfaces to this end.

Rick Mullin (1997) referred to that the built-in packaged software program options are being constructed round frequent records technological know-how requirements and adaptable to precise industry to limit training/running cost. Information networking and strategic alliances with suppliers or distribution channel companions or logistic operators have end up a compelling want to decrease cycle times. Companies effected by way of world classification competition, bench mark no longer solely their merchandise however additionally their key enterprise processes. Therefore, groups are no longer inclined to automate present procedures blindly. Rather, desire to radically change enterprise techniques with first-class enterprise practices. Information networking and strategic alliances with suppliers or distribution channel companions or logistic operators have end up a compelling want to minimize cycle times. According to Parr and Shanks (2000), Vanilla implementation is safer alternative for the implementation with minimal customization. Rao (2000) noted that eighty percentage of the advantages of ERP got here out of integration. There need to be a clear coverage to put in force the ERP in the "VANILLA" shape except the customization. Grossman and Walsh (2004), has the view that the pilot segment is only a prototyping phase. Once that section is whole and all the information is loaded to the gadget then the stress testing ought to be carried out to locate out the imperative elements which assist in the implementation of ERP. According to Peffers et al. (2003), senior managers have determined CSF to be attractive for IS planning due to the fact they assist justify the improvement of strategically essential new systems, the advantages of which can also be difficult to quantify. ERP structures enable the integration of functions, divisions of groups in phrases of statistics change and flow, and the integration of commercial enterprise features as various as accounting, finance, human resources, operations, sales, marketing, consumer statistics and even the furnish chain. Mohammad et al. (2005) mentioned that thinking about ERP implementation as an IT challenge is a hazard itself. If the implementation is dealt with as a Project, the ERP machine will by no means be carried out to its full capabilities. In such instances the commercial enterprise procedure will now not be true reengineered and aligned with the software program requirements, and staffs swill resist. Park and Kaushik (2005), the ERP mission want to be primarily based on an enterprise-wide diagram and it is now not viable to begin with portions and then attempt tointegrate the software program issue later on. According to Dezdar and Ainin (2009), In spite of the many benefits, there are wide varieties of hassle in the adoption of ERP. A latest lookup displays that extra than $90 \%$ of ERP. Implementations have been delayed and required extra price range amounts.

Finney and Corbett (2007) has recognized a hole in the literature which there is a want to become aware of the fundamental elements for the profitable implementation of ERP in SMEs. Wang et al., (2005) It is critical to discover factors main to success of ERP structures Implementation. According to Dezdar and Ainin,(2009) :Global ERP providers are now attempting to lengthen their market to groups in turns many creating nations are now imposing ERP systems, however there was no longer been a good deal lookup on the success elements of ERP tasks in these regions/countries. Identification of Small and Medium Size Enterprise (SMEs): Small and medium businesses (SMEs) are regarded as the spine of the financial system of many nations round the world. There is no single generalized definition for the identification of SMEs.

Ibrahim and Goodwin, (1986):Some of the most extensively used standards to discover SME encompass size, variety of employees, income volume, asset dimension and capital requirement According to the UK Department of Trade and Industry, SMEs encompass the business enterprise that that have much less than 250 personnel and micro SMEs that have much less than 10 employees. Organization for Economic Cooperation and Development (OECD) defines organizations with up to 19 personnel as 'very small', between 20 and ninety-nine personnel as 'small, from a hundred to 499 personnel as medium, and over 500employees as giant enterprises. However, many businesses in some growing international locations with a hundred to 499 personnel are considered as surprisingly
Published By:

Blue Eyes Intelligence Engineering \& Sciences Publication (C) Copyright: All rights reserved. t and $\mathrm{Hu}_{\mathrm{m}}$ ब5 ¿ $(10)$ IJMI 
'large' firms. Multilateral Investment Guarantee Agency (MIGA) has currently developed a assurance program, known as the Small Investment Program (SIP) that is in particular designed for SMEs. MIGA defines SMEs, for insurance below this program, as companies with no longer greater than 300 employees, fee of property now not exceeding US \$ 15 million and annual income now not exceeding US \$ 15 million. The European Union defines SMEs as organizations that have personnel of much less than 250, with a turnover no longer exceeding Euro 50 million. In India the SMEs are no longer properly defined. The inside team set up through the Reserve Bank of India has lately advocated that the gadgets with funding in plant and equipment in extra of Small Scale Industries (SSI) restrict and up to Rs. 10 cores may additionally be handled as medium enterprises. The US Small Business Act 1953 states that a small commercial enterprise subject is one that is independently owned and operated and which is now not dominant in its area of operation. The dimension requirements are damaged through NAICS enterprise classification and are based totally on two matters (a) Size requirements in tens of millions of dollars; and (b) via quantity of employee. In most industries, five hundred is the most for small businesses, even though thereare industries the place a enterprise can have 1000-1500 personnel but nonetheless viewed "small business".

\section{CRM: The Business Focus}

A restrained view of Customer Relationship Management would be database advertising and marketing focusing on how promotional advertising and marketing is linked to database administration tools. A extra extensively widespread concept states that it is the utility of science that emphasizes on character or one to one relationships with clients with the aid of integrating database expertise with the lengthy time period possibilities of boom and consumer loyalty. Managing a profitable CRM implementation requires an built-in and balancedapproach to technology, process, and humans (Chen, J. Injazz, Popvich, K., 2001) CRM or Customer Relationship Management is an organization large initiative that belongs to all areas of an employer (Singh D. and Agrawal, D.P. 2003). It displays the complete method and system of acquiring, retaining, and partnering with selective clients to create most fulfilling fee for the agency and the customer. Customer Relationship Management is a time period for the methodologies, applied sciences and e-commerce abilities used by using the corporations to control client relationships. In specific CRM software program applications resource the interplay between the consumer and the company, enabling the organization to co-ordinate all of the verbal exchange efforts so that the patron is introduced with a unified message and image.CRM coordinates contact factors round a frequent view of the patron (Eckerson and Watson, 2000). As the commercial enterprise receives large and quantity of client relationships to be managed amplify exponentially, it calls for integration of unique commercial enterprise departments to collaborate the consumer statistics to grant a unified view of patron interplay to serve the clients better. Customer Relationship Management is the strategic manner of shaping the interactions between a business enterprise and its clients with the intention of maximizing contemporary and lifetime fee of clients for the corporation as nicely as maximizing pleasure for clients (Rajagopal, Sanchez and Romulo
Sanchez, 2005).CRM can be seen as an software of one-toone advertising and marketing and relationship marketing, responding to an character consumer on the foundation of what the patron says and what else is recognized about that patron (Peppers, Rogers and Dorf, 1999).It is a administration method that permits establishments to identify, attract, and enlarge retention of worthwhile clients by using managing relationships with them (Hobby, J., 1999) eighty four and similarly figuring out strategically massive clients (Buttle, F., 2001) . CRM is an IT enabled enterprise strategy, the results of which optimize profitability, income and client delight by using organizing around patron segments fostering customer-satisfying behavior and imposing a customercentric manner A specified evaluation of on hand definitions in the area of CRM helps us collect the following definition- Customer Relationship Management is a complete commercial enterprise method to empower the inner functioning of an enterprise with the goal to identify, acquire, deliver, improve and continue customers. With the use of ever altering technology, this procedure seeks to combine more than a few features of an organization, such that it will become fine and environment friendly in the lengthy run. This allows the employer to have a high consumer share and market share to achieve a lengthy time period aggressive advantage. CRM is necessary due to the fact it charges 6 to 7 instances extra to collect a new consumer than to hold an present customer. An make bigger in patron retention charge with the aid of $5 \%$ can perchance extend the earnings by means of up to 95\%. Further, all clients do no longer make a contribution equally to the firm's backside line and for that reason are now not equally precious for the employer (Natrajan, R. and Shekhar, B., 2010). The cost of focused on the proper variety of clients has emerge as so necessary that the complete success and failure of an organization relies upon on client acquisition and retention. It is for this motive that technological know-how has come to be very necessary in advertising in the structure of CRM. To grant a healthy appreciation about customers, fine facts technology and information evaluation is very important, backed with excellent facts mining, businesses can reap such benefits.

\section{RESEARCH OBJECTIVES}

1. To find out about the CRM things to do on imposing ERP options in engineering organizations in context to Gujarat.

2. To have a look at the relationship between CRM: The Business Focus component and statistics best of ERP answer in context to engineering corporations of Gujarat State.

3. To look at the relationship between CRM: The Business Focus element and gadget nice of ERP answer in context to engineering groups of Gujarat State.

4. To find out about the relationship between CRM: The Business Focus issue and machine use of ERP answer in context to engineering corporations of Gujarat State.

5. To learn about the relationship between CRM: The Business Focus thing and appropriateness of ERP answer in context to engineering organizations of Gujarat State.

6. To decide the most influential element to CRM: The Business Focus issue amongst data quality, machine quality, gadget use and appropriateness. 


\section{Hypothesis}

H01: There is no relationship between CRM: The Business Focus and data best of ERP answer in context to engineering groups of Gujarat State.

H02: There is no relationship between CRM: The Business Focus and machine fine of ERP answer in context to engineering organizations of Gujarat State.
H03: There is no relationship between CRM: The Business Focus and gadget use of ERP answer in context to engineering corporations of Gujarat State.

H04: There is no relationship between CRM: The Business Focus and appropriateness of ERP answer in context to engineering organizations of Gujarat Stat

\section{Pearson Correlation Test}

In this Learning, Pearson correlation test is conducted to determine the relationship amongst the factors i.e. IQ, S, SU, A and CRMBF.

\begin{tabular}{|l|l|l|l|l|l|l|}
\hline \multicolumn{2}{|l}{ Correlations (Table-4.29) } & IQ & SQ & SU & A & CRMBF \\
\hline & Pearson Correlation & 1 & $.618^{* *}$ & $.735^{* *}$ & $.678^{* *}$ & $.612^{* *}$ \\
\hline & Sig. (2-tailed) & &. .000 & .000 & .000 & .000 \\
\hline & $\mathrm{N}$ & 372 & 372 & 372 & 372 & 372 \\
\hline SQ & Pearson Correlation &. $.618^{* *}$ & 1 & $.654^{* *}$ & $.669^{* *}$ & $.650^{* *}$ \\
\hline & Sig. (2-tailed) & .000 & & .000 & .000 & .000 \\
\hline & $\mathrm{N}$ & 372 & 372 & 372 & 371 & 372 \\
\hline SU & Pearson Correlation & $.735^{* *}$ & $.654^{* *}$ & 1 & $.650^{* *}$ & $.608^{*}$ \\
\hline & Sig. (2-tailed) & .000 & .000 & & .000 & .000 \\
\hline & $\mathrm{N}$ & 372 & 372 & 372 & 371 & 372 \\
\hline A & Pearson Correlation & $.678^{* *}$ & $.769^{* *}$ & $.650^{* *}$ & 1 & $.709^{* *}$ \\
\hline & Sig. (2-tailed) & .000 & .000 & .000 & & .000 \\
\hline & $\mathrm{N}$ & 371 & 371 & 371 & 371 & 371 \\
\hline CRMBF & Pearson Correlation & $.612^{* *}$ & $.669^{* *}$ & $.608^{*}$ & $.709^{* *}$ & 1 \\
\hline & Sig. (2-tailed) & .000 &. .000 & .000 & .000 & \\
\hline & $\mathrm{N}$ & 372 & 372 & 372 & 371 & 372 \\
\hline$* *$ Correlation is significant at the 0.01 level (2-tailed). & & & \\
\cline { 2 - 6 } & & & & & \\
\hline
\end{tabular}

(1) Factor Analysis: Information Quality (IQ)

\section{Correlation Matrix (Table-4.30)}

\begin{tabular}{|l|l|l|l|l|l|l|l|l|l|l|}
\hline \multicolumn{2}{|l}{} & IQ2 & IQ4 & IQ6 & IQ7 & IQ8 & IQ9 & IQ10 & IQ11 & IQ12 \\
\hline Correlation & IQ2 & 1.000 & .705 & .328 & .741 & .704 & .703 & .534 & .174 & .175 \\
\hline & IQ4 & .705 & 1.000 & .193 & .611 & .674 & .635 & .569 & .158 & .132 \\
\hline & IQ6 & .328 & .193 & 1.000 & .309 & .120 & .268 & -.089 & -.076 & -.122 \\
\hline & IQ7 & .741 & .611 & .309 & 1.000 & .586 & .970 & .464 & .053 & .131 \\
\hline & IQ8 & .704 & .674 & .120 & .586 & 1.000 & .595 & .725 & .195 & .105 \\
\hline & IQ9 & .703 & .635 & .268 & .970 & .595 & 1.000 & .487 & .083 & .173 \\
\hline & IQ10 & .534 & .569 & -.089 & .464 & .725 & .487 & 1.000 & .289 & .249 \\
\hline & IQ11 & .174 & .158 & -.076 & .053 & .195 & .083 & .289 & 1.000 & .632 \\
\hline & IQ12 & .175 & .132 & -.122 & .131 & .105 & .173 & .249 & .632 & 1.000 \\
\hline
\end{tabular}

Table-4.30 indicates the matrix of correlations. In factor analysis, it is desired to have highly correlated variables and that is why correlation matrix is taken into considered for this analysis.

Published By:

Blue Eyes Intelligence Engineering \& Sciences Publication 
The Learning on CRM in Erp- with Special References to Selected Engineering Companies in Gujarat

(2) Factor Analysis: System Quality (SQ)

\begin{tabular}{|l|l|l|l|l|l|l|l|l|l|l|}
\hline \multicolumn{2}{|l}{ Correlation Matrix (Table-4.34) } \\
\hline \multirow{4}{*}{$\begin{array}{l}\text { Correlati } \\
\text { on }\end{array}$} & SQ1 & 1.000 & .260 & .097 & .170 & .122 & .172 & .022 & .085 & .045 \\
\cline { 2 - 11 } & SQ2 & .260 & 1.000 & .205 & .120 & .184 & .224 & .144 & -.118 & -.061 \\
\cline { 2 - 11 } & SQ3 & .097 & .205 & 1.000 & .311 & .682 & .358 & .204 & -.197 & -.070 \\
\cline { 2 - 11 } & SQ4 & .170 & .120 & .311 & 1.000 & .520 & .486 & .253 & .049 & .127 \\
\cline { 2 - 11 } & SQ5 & .122 & .184 & .682 & .520 & 1.000 & .745 & .201 & -.148 & -.004 \\
\cline { 2 - 10 } & SQ6 & .172 & .224 & .358 & .486 & .745 & 1.000 & .145 & -.128 & -.001 \\
\cline { 2 - 10 } & SQ7 & .022 & .144 & .204 & .253 & .201 & .145 & 1.000 & -.163 & -.029 \\
\cline { 2 - 10 } & SQ8 & .085 & -.118 & -.197 & .049 & -.148 & -.128 & -.163 & 1.000 & .637 \\
\cline { 2 - 10 } & SQ9 & .045 & -.061 & -.070 & .127 & -.004 & -.001 & -.029 & .637 & 1.000 \\
\hline
\end{tabular}

Table-4.34 indicates the correlation matrix amongst SQ1-12. SQ10-12 is excluded for the reason of high -ve correlations. The value in bold letter as shown in table4.34 is considered.

(3) Factor Analysis: System Use (SU)

\begin{tabular}{|l|l|l|l|l|l|l|l|l|}
\hline \multicolumn{2}{|l}{ Correlation Matrix (Table-4.39) } \\
\hline \multirow{4}{*}{ Correlation } & SU5 & 1.000 & .659 & .634 & .193 & .200 & .166 & .200 \\
\cline { 2 - 9 } & SU6 & .659 & 1.000 & .979 & .391 & .120 & .105 & .129 \\
\cline { 2 - 9 } & SU7 & .634 & .979 & 1.000 & .411 & .106 & .091 & .108 \\
\cline { 2 - 9 } & SU8 & .193 & .391 & .411 & 1.000 & .041 & .030 & .003 \\
\cline { 2 - 9 } & SU10 & .200 & .120 & .106 & .041 & 1.000 & .618 & .476 \\
\cline { 2 - 9 } & SU11 & .166 & .105 & .091 & .030 & .618 & 1.000 & .670 \\
\cline { 2 - 9 } & SU12 & .200 & .129 & .108 & .003 & .476 & .670 & 1.000 \\
\hline
\end{tabular}

Table-4.39 indicates the results on correlation matrix amongst SU1-12. Here, SU1-4 and SU9 are excluded because of negative and very low correlation is observed. The bold observations' in table-4.39 are treated as highly correlated.

(4) Factor Analysis: Appropriateness (A)

\section{Correlation Matrix(Table-4.44)}

\begin{tabular}{|l|l|l|l|l|l|l|l|l|l|}
\hline \multicolumn{2}{|c}{} & A2 & A3 & A4 & A5 & A6 & A8 & A10 & A12 \\
\hline Correlation & A2 & 1.000 & .226 & & & & & & \\
\hline & A3 & .226 & 1.000 & & & & & & \\
\hline & A4 & .418 & .779 & 1.000 & & & & & \\
\hline & A5 & .123 & .647 & .286 & 1.000 & & & & \\
\hline & A6 & .251 & .688 & .514 & .469 & 1.000 & & & \\
\hline & A8 & .658 & .133 & .256 & .333 & .447 & 1.000 & & \\
\hline & A10 & .516 & .399 & .549 & .434 & .644 & .635 & 1.000 & \\
\hline & A12 & .114 & .119 & .055 & .242 & .056 & .009 & -.009 & 1.000 \\
\hline
\end{tabular}

Table-4.44 indicates the results on correlation matrix amongst A1-12. Here, A1,A7 and A9 are excluded because of negative and very low correlation is observed. The bold observations' in table-4.39 are treated as highly correlated. 
(5) Factor Analysis: CRM: The Business Focus (CRMBF)

The last factor is also tested for the same and output is interpreted in the following manner for correlation matrix, KMO and Bartlett's Test, communalities, total variance explained, screen plot and rotated component matrix with a view to determine variance and correlations amongst variables.

\begin{tabular}{|c|c|c|c|c|c|c|c|c|}
\hline & & CRMBF1 & CRMBF2 & CRMBF3 & CRMBF4 & CRMBF5 & CRMBF6 & CRMBF7 \\
\hline \multirow{7}{*}{$\begin{array}{l}\text { Correlat } \\
\text { ion }\end{array}$} & CRMBF1 & 1.000 & & & & & & \\
\hline & CRMBF2 & .623 & 1.000 & & & & & \\
\hline & CRMBF3 & .597 & .614 & 1.000 & & & & \\
\hline & CRMBF4 & .411 & .582 & .578 & 1.000 & & & \\
\hline & CRMBF5 & .109 & .723 & .676 & .633 & 1.000 & & \\
\hline & CRMBF6 & .838 & .651 & .606 & .639 & .651 & 1.000 & \\
\hline & CRMBF7 & .540 & .679 & .784 & .640 & .659 & .670 & 1.000 \\
\hline
\end{tabular}

Table-4.49 indicates the results on correlation matrix amongst CRMBF1-12. Here, CRNBF8-10 are excluded because of negative and very low correlation is observed. The bold observations' in table-4.39 are treated as highly correlated.

\section{CONCLUSION}

The sample respondents in the present Learning are evaluated by analyzing the responses obtained through the primary data collection by applying appropriate statistical techniques such as parametric tests. The demographic section for analysis and interpretation for hypothesis testing is not conducted in this Learning because of non-formation of objectives in this regards for the following reasons.

1. The respondents have not diverse cultural background in selected 15 engineering SMEs of Gujarat state.

1. McGaughey, R. E., \&Gunasekaran, A. (2007). Enterprise Resource

2. Davenport, T. and Klahr, P. (1998), "Managing customer supportknowledge", California. Management Review, Vol. 40 No. 3 , pp. 195-208.

3. Møller, C. "ERP II: a conceptual framework for next-generation enterprisesystems?," Journal of Enterprise Information Management (18:4) 2005, pp483-497.

4. Rashid, A., D. Harris, P.A Hollington and R.A. Khattak. 2002. Onfarm seedpriming: a key technology for improving the livelihood of resource poorfarmers on saline lands. Centre for Arid Zone Studies, University of Wales,UK

5. Bond, T. C. and Bergstrom, R. W.: Light absorption by carbonaceousparticles: an investigative review, Aerosol Sci. Tech., 40, 27-67, 2006

6. M.L. Markus, S. Axline, D. Petrie, and C. Tanis, "Learning from Adopters'Experiences with ERP: Problems Encountered and Success Achieved",Journal of Information Technology, vol. 15, 2000, pp. 245-265

7. L.V. Redman et al 1923 , The Romance of Research, p.10

8. C. R. Kothari, Research Methodology, Methods and techniques (New AgeInternational

9. Achanga, P., Shehab, E., Roy, R. and Nelder G. (2006), "Lean impact assessment atthe conceptual design stage", Proc. of the 16th International Design Seminar (CIRP2006), CIRP Publishers, Kananaskis, Alberta, Canada.

10. Al-Mashari, M. and Zairi, M. (1999), “BPR implementation process: an analysis ofkey success and failure factors", Business Process Management Journal, Vol. 5 No.1, pp. 87-112

11. Ansari, Asim and Carl F. Mela., (2003), "E-Customization “, Journal of MarketingResearch, Volume 40, Number 2, p.p 131-145. Planning(ERP): Past, Present and Future (pp. 23-35): IGI Global.

2. The respondents have academic qualification does not affect the working style with CRM and ERP software and usage of output.

3. The marital status, experience and income have not also significant response on the same and as a result, objectives are not formed in this regards.

Position component indicates that the ratio of managerial and non-managerial position is registered at 1:6 i.e. $5.79 \%$ which cannot allow constituting objective on "position" component. Because, as a rule of thumb there should be minimum 10\% respondents in managerial position (55) as samples for this Learning.

\section{REFERENCES}

12. ASKENAS, L. 2003. Five Roles of an Information System. Informing science, 6,209.

13. Au, W. H., \& Chan, K. C. C. (2003). Mining fuzzy association rules in a bankaccountdatabase. IEEE Transactions on Fuzzy Systems, 11, 238-248

14. Axline, S., Markus, M. L., Petrie, D., \& Tanis, C. (2001). Learning from experienceswith ERP: problems encountered and success achieved. In Shanks G., Seddon P. B.,\& Willcocks L. P. (Eds.) Second-wave enterprise resource planning systems (p. 23-54). Edinburgh: Cambridge University Press.

15. Bailey, J. E. and Pearson, S. W. 1983. Development of a tool for measurement andanalysing computer user satisfaction. Managemen Science, 29(5): 530-545.

16. Ballou, D.P., and Pazer, H.L., 1985, Modeling data and process quality in multiinput,multioutput information systems. Managemen Science. 31(2): 150-162.

17. Berry, L.L. andWall E. (2006), "Service Clues and Customer assessment of theService Experience", Academy of Management Perspectives

18. Berson, A.; Smith, S.; Thearling, K.; 1999, Building data mining applications forCRM, McGraw-Hill, USARedman , T.C. (2005) "Measuring Data Accuracy A Framework and Review." InInformation Quality Advances in Management Information Systems, ed: Zwass, V.,21 - 36 London: M. E. Sharpe Inc.

19. Redman TC, 1995, 'Improve data quality for competitive advantage', SloanManagement Review, Vol.36, No 2, pp.99-107.

Published By:

Blue Eyes Intelligence Engineering \& Sciences Publication 
20. Reinartz, W. J., \& Kumar, V. (2003), "The impact of customer relationshipcharacteristics on profitable lifetime duration", Journal of Marketing, Volume 67,Number 1, p.p 77-99.

21. Rigby, D.K., F.F. Reichheld, and P. Schefter. 2002. Avoid the four perils of CRM.Harvard Business Review 80(2): 101-109.

22. RIKHARDSSON, P. \& KRÆMMERGAARD, P. 2006. Identifying the Impacts ofEnterprise

System Implementation and Use: Examples from Denmark. InternationalJournal of Accounting Information Systems, 7, 36-49.

23. "The Impact of CRM in ERP specially for selected Engineering Companies in Vadodara" . International Journal of Advance Research and Innovative Ideas in Education (IJARIIE). Page Number: 144-149, ISSN No: 2395-4396 Volume -02 Issue-02 March, 2016

24. A Study paper on CRM in ERP with special references to selected engineering companies in Gujarat" VSRD-TNTR International Journal of Technical \&Non Technical Research. Page Number: 68-70 Volume-IX Special Issue in February, ISSN No: E-ISSN: 0976-7967 P-ISSN: 2319-2216, February, 2018

25. Awareness about CRM in ERP: A case study for selected Pharmaceutical Companies in Vadodara in Journal of Emerging Technologies and Innovative Research (An International Open Access Journal), Page Number: 748-754, ISSN No: : 2394 - 5162 Volume 06 Issue- 03, March 2019

26. A Study Paper on CRM in ERP with special reference to selected Cement Companies in Gujarat, International Journal of Gujarat Research Society, Page Number: 114-119 Gujarat Research Society, ISSN No: 0374-8588 Volume 21 Issue- 09,November 2019

27. A study paper on the scope of CRM in small scale production units of Vadodara" in Key to success for Managing Global Business in Turbulent times. Page numbers 401-407, M. J. College of Commerce (Constituent College of M. K. Bhavnagar University) Bhavnagar 364001. Gujarat.ISBN No: 978-81-929516-0-7, May, 2015.

\section{AUTHORS PROFILE:}

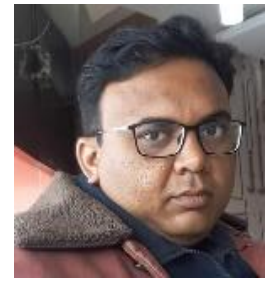

Dr. Mehul Patel, is the person who has knowledge of various subjects. He has completed his Ph. D, MBA, MCA and M. Sc in Value Education \& Spirituality and Various Certificate Courses. Presently he is serving in C.P.Patel \& F.H.Shah Commerce College, ANAND since 3 Years. He has 21years experience in various categories like research, system analysis, and customization at user end. He taught various faculties like computer science, management, statistics, and mathematics and operation research. He produced 32 Research papers, 3 books published and attended 29 Seminar/Workshops. He is review member in various international journals like JETIR, IJCRT, IARA and IJSRSET. As well as Editor in International Journal of Scientific Research in Science, Engineering and Technology (IJSRSET), Print ISSN: 2395-1990, Online ISSN : 2394-4099, Associate Editor of International Journal of Advance \& Innovative Research (ISSN: 2394-7780) and International Journal of Research in Management and Social Sciences (ISSN: 2322 - 0899). Associate Editor of International Journal of Commerce \&Management Research ISSN: 2455-1627, Associate Editor of National Journal of Multidisciplinary Research \& Development ISSN: 2455-9040, and Editorial Member in International Journal for Innovative Research in Multidisciplinary Field (ISSN: 2455-0620) \& International Journal of Research Culture Society (ISSN: 2456-6683).

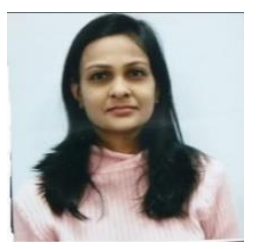

Ms. Manisha Ben Jaiswal, is an author, researcher as well as an IT consultant. She had published three books title as Software Engineering, Computer Concepts and Application- II, and Relational Database with ISBN number 978-93-5163-192-7, 978-9389627-40-4 and 978-93-89627-52-7 respectively. She had published a paper in state and national level conferences, and also active in an international paper publication in various journals. She guided on several Industrial Projects and Dissertation for graduate-level students and staff. She acted as an Internal Guide as well as the External Examiner, and Supervisor of Gujarat Technological University, India. She is active as a reviewer author in the international journal and working on IT consultants in a well-known organization 